\title{
P01-293
}

\section{GENDER DIFFERENCES IN BRAIN SEROTONIN SYNTHESIS IN INDIVIDUALS WITH MAJOR DEPRESSIVE DISORDER: A A-} $\left[{ }^{11} \mathrm{C}\right] \mathrm{MT}$ PET IMAGING STUDY

\author{
B.N. Frey ${ }^{1,2}$, I. Skelin $^{1}$, Y. Sakai ${ }^{1}$, M. Nishikawa ${ }^{1}$, M. Diksic $^{1}$ \\ ${ }^{1}$ Department of Neurology and Neurosurgery, and Montreal Neurological Institute, McGill University, Montreal, ${ }^{2}$ Department of \\ Psychiatry and Behavioural Neurosciences, McMaster University, Hamilton, Canada
}

Objective: Women are at higher risk than men to develop major depressive disorder (MDD), but the mechanisms underlying the higher risk for MDD in women are unknown. There is a wealth of data showing gender differences in brain morphology and function. In addition, preclinical studies have demonstrated reciprocal relationships between ovarian hormones and serotonin neurotransmission. Thus, gender differences in brain serotonin neurotransmission are potential underlying mechanisms. In the present study, we compared normalized $\alpha-\left[{ }^{11} \mathrm{C}\right]$ methyl-L-tryptophan brain trapping constant $\left(\alpha-\left[{ }^{11} \mathrm{C}\right] \mathrm{MTrp} \mathrm{K}^{*} ; \mathrm{ml} / \mathrm{g} / \mathrm{min}\right)$, an index of serotonin synthesis, between men and women with MDD.

Method: $\alpha-\left[{ }^{11} \mathrm{C}\right] \mathrm{MTrp} \mathrm{K}^{*}$ was measured in 25 medication-free individuals with MDD (13 females and 12 males) using positron emission tomography. Comparisons of normalized $\alpha-\left[{ }^{11} \mathrm{C}\right] \mathrm{MTrp} \mathrm{K}^{*}$ values between men and women were conducted at the voxel level using Statistical Parametric Mapping 2 (SPM2) analysis.

Results: Women with MDD displayed significantly higher $(p<0.005)$ normalized $\alpha-\left[{ }^{11} \mathrm{C}\right] \mathrm{MTrp} \mathrm{K}^{*}$ than men in the inferior frontal gyrus, anterior cingulate cortex (ACC), parahippocampal gyrus, precuneus and superior parietal lobule, and occipital lingual gyrus.

Conclusions: This finding suggests that depressive women have higher serotonin synthesis in multiple regions of the prefrontal cortex and limbic system involved with mood regulation. Gender differences in brain serotonin synthesis may be associated with higher risk for MDD in women because extra levels of tissue 5-HT could create non-physiological connections influencing changes in mood. 